\title{
COLD JUNCTION PLATE OPTIMIZATION FOR THE NIGHTTIME SOLAR CELL ${ }^{\text {TM }}$
}

\author{
Ronald J. Parise \\ Parise Research Technologies \\ 101 Wendover Road \\ Suffield, CT 06078 \\ Phone: (860) 668-4599 \\ e-mail: www.rjparise@hotmail.com
}

\author{
G. F. Jones \\ Depart. Of Mech. Engrg. \\ Villanova University \\ Villanova, PA 19085 \\ Phone: (610) 519-4985
}

\section{ABSTRACT}

The primary objective of the Nighttime Solar Cell ${ }^{\mathrm{TM}}$ is to produce electric power at night. The cell can be used to complement daytime photovoltaic electrical energy production, or as a stand-alone device can produce electrical power both night and day in lowwattage applications. The Nighttime Solar Cell ${ }^{\mathrm{TM}}$ operates with a thermoelectric generator (TEG) utilizing the ambient or its surroundings as the source of thermal energy while deep space provides a thermal sink. The cold junctions of the TEG are insulated from the surroundings with a vacuum to improve overall effectiveness. The Cold Junction Plate (CJP) inside the cell links the TEG's cold junctions to the thermal sink, acting as a heat spreader (HTS) to increase the heat flux from the device. The thermal model describing the operation of the cell has been enhanced to investigate different configurations for the HTS. For this application, the HTS utilizes radiation heat transfer to reject the waste heat to the thermal sink. A simple onedimensional model is used to investigate the effect of the HTS geometry on the cell. Typically used in high power electronic heat dissipation, here the HTS allows for a greater influence by the thermal sink to increase cell output. Data for two-dimensional, radiatively cooled HTSs is presented, comparing cylindrical and rectangular geometries. The TEG module is modelled as a heat source in the center of the HTS. The results show that for typical Nighttime Solar $\mathrm{Cell}^{\mathrm{TM}}$ thermal systems, square TEG modules can be modeled as cylindrical to match round heat spreaders with little loss of accuracy. The analysis also shows that the HTS thickness is favorable for using copper CJPs to increase the heat transfer to deep space while reducing the mechanical stress on the TEGs. Also, projected performance of a prototype cell currently being built illustrates the effectiveness of high junction density modules for future cell development.

\section{INTRODUCTION}

The Nighttime Solar Cell ${ }^{\mathrm{TM}}$ is a clean, renewable energy source that produces electric power day and night. ${ }^{1,2}$ For nighttime energy production, the solidstate device works on the simple principle of a thermoelectric generator (TEG) operating in the temperature difference that exists between deep space at an effective temperature of $4 \mathrm{~K}$ and the surrounding ambient temperature (nominally 295K). Thus the ambient or surroundings of the device are the source of thermal energy, while deep space provides a thermal $\operatorname{sink} .^{3}$

For daytime electrical energy production, the Nighttime Solar Cell ${ }^{\mathrm{TM}}$ can use solar energy as the thermal source and the ambient as the thermal sink. Or it can continue to operate in nighttime mode, depending on mounting inclination and/or strategic cell shading. 4,5

The cold junctions of the TEGs are in thermal contact with the Cold Junction Plate (CJP), also enclosed in the vacuum with the module. The CJP radiates the cell's waste thermal energy in select IR bands out of the vacuum cell through an aperture covered by a spectrally select window, hermetically sealed to the cell. The selected IR bands are transparent to both the spectral window and the earth's atmosphere. The waste energy then travels unattenuated through the atmosphere into deep space. Figure 1 shows a schematic drawing of the Nighttime Solar Cell ${ }^{\mathrm{TM}}$.

The driving force for nighttime operation of the device is the radiation heat transfer link between the terrestrially mounted cell and the thermal sink of deep space. This radiative link is affected by the thermal, spectral and geometric properties of the CJP, as well as atmospheric conditions. The CJP design as a thermal heat spreader is key to successful operation of the Nighttime Solar Cell ${ }^{\mathrm{TM}}$. 


\section{BACKGROUND}

A thermal model has been developed to simulate both daytime and nighttime operation of the Nighttime Solar $\mathrm{Cell}^{\mathrm{TM}}$. The model is being used to determine operational parameters for building a prototype. For example, the CJP typically is larger than the footprint of the TEG module, creating a type of "fin", or more appropriately, a heat spreader (HTS), around the module periphery, as well as on the module end face.

These HTSs can be used in many heat transfer applications where quick dissipation of the thermal load is necessary, especially in high power electronic systems. Typically in these systems, conduction and/or convection would be the sole means of removing the heat from the HTS, for example, in computers or other electronic devices. Heat pipes are being considered for certain applications where very high heat fluxes are involved. $^{6}$

For the Nighttime Solar Cell ${ }^{\mathrm{TM}}$, the HTS removes the heat from the cold junctions by conduction, then utilizes radiation heat transfer to move the thermal energy away from the cell into deep space. Hence this unique use of HTSs.

For this application, the HTS has two advantages: (1) more of the TEG end junctions' area is "exposed" to deep space, increasing cell output; and, (2) depending on CJP (HTS) geometry and material, the conduction to radiation thermal energy conversion is more effective.

Note that the finish or coating on the HTS surface facing deep space is critical for radiative properties. High emissivity $(>0.94)$ in the $8 \mu \mathrm{m}$ to $13 \mu \mathrm{m}$ range reduces IR energy attenuation in the atmosphere, improving the performance of the device. Although coatings are being developed for high power fluxes, ${ }^{7}$ increased emissivity for the Nighttime Solar Cell's ${ }^{\text {TM }}$ HTS can improve performance considerably.

Also, based on the thickness, size and material of the HTS or CJP, an undue mechanical stress is put on the long, slender TEG elements, as well as affecting thermal performance. The model thus investigates the geometry and effectiveness of the radiatively transmitting CJP (HTS).

This research is an on-going effort to develop a reliable, safe, inexpensive, alternate source of electric power at night. Previous studies have shown that $1 \mathrm{~mm}$ x $1 \mathrm{~mm}$ TEG elements in a $6 \mathrm{~cm} \times 6 \mathrm{~cm}$ cell can produce about $8 \mathrm{~mW}$ of continuous electrical power during nighttime operation.

The model is now being used to predict the performance of a prototype Nighttime Solar Cell ${ }^{\mathrm{TM}}$ that is being built with a module that will use $0.635 \mathrm{~mm} \mathrm{x}$ $0.635 \mathrm{~mm}$ TEG elements about $2.5 \mathrm{~cm}$ long.

\section{THERMAL MODEL}

The thermal model, developed from fundamental principles, determines the temperature difference between the hot and cold junctions of the bismuth telluride TEGs, based on the equilibrium temperature attained by the CJP (HTS) surface facing deep space. Figure 1 shows the physical configuration and parameters utilized in the model when using deep space as the thermal sink during nighttime operation. The orientation of the cell is such that the CJP (HTS) is parallel to the horizontal. The thermal source of energy to the module is the ambient.

The TEG junctions are copper and the HTS can be aluminum or copper. The thermal conductivities of copper and/or aluminum are sufficiently large so that the temperature gradients are small through the thickness of each.

For this investigation, the thickness of the CJP as the HTS and the extension beyond the TEG module is varied to determine its effectiveness. The thermal model will also use the TEG geometry of the module being built to determine the performance of the prototype. Future research will compare the model performance with the prototype data.

\section{$\underline{\text { Radiation Model }}$}

Radiation heat transfer, with the CJP (HTS) inside the vacuum, includes the radiosity $\mathrm{J}_{\mathrm{C}}$ of the plate, the fraction of energy from the night sky that is transmitted through the spectral window and not attenuated in the atmosphere, emission from the window, and the fraction of the radiosity that is reflected from the window. The net radiative heat flux of the HTS is

$$
\mathrm{q}_{\mathrm{c}}=\left(1-\rho_{\mathrm{W}}\right) \mathrm{J}_{\mathrm{c}}-\tau_{\mathrm{w}} \sigma \mathrm{T}_{\mathrm{S}}^{4}-\varepsilon_{\mathrm{W}} \sigma \mathrm{T}_{\mathrm{w}}{ }^{4}
$$

where $T_{S}$ is the temperature of the sky, $T_{W}$ the temperature of the window, $\rho_{\mathrm{W}}, \tau_{\mathrm{w}}, \varepsilon_{\mathrm{W}}$ are the radiative 
properties of reflectivity, transmissivity and emissivity of the window. ${ }^{4}$

The model also includes convection on the outside of the spectral window and can include the effects of conduction inside the chamber for a less than perfect vacuum. An energy balance on the window is

$$
\begin{gathered}
\mathrm{h}_{\mathrm{w}}\left(\mathrm{T}_{\infty}-\mathrm{T}_{\mathrm{W}}\right)=2 \varepsilon_{\mathrm{w}} \sigma \mathrm{T}_{\mathrm{w}}{ }^{4}-\varepsilon_{\mathrm{w}} \sigma \mathrm{T}_{\mathrm{s}}{ }^{4} \\
-\varepsilon_{\mathrm{w}} \mathrm{J}_{\mathrm{c}}+\left(\mathrm{k}_{\mathrm{a}} / \mathrm{L}_{\mathrm{a}}\right)\left(\mathrm{T}_{\mathrm{c}}-\mathrm{T}_{\mathrm{w}}\right),
\end{gathered}
$$

where $h_{W}$ is the convective heat transfer coefficient at the glass surface, $\mathrm{T}_{\infty}$ the ambient temperature, $\mathrm{T}_{\mathrm{c}}$ the CJP (HTS) temperature, $\mathrm{k}_{\mathrm{a}}$ the thermal conductivity of air inside the cell, and $\mathrm{L}_{\mathrm{a}}$ the air gap between the spectral plate and the window. ${ }^{5}$

\section{$\underline{\text { Heat Conduction and Thermoelectric Model }}$}

The CJP (HTS) is in thermal contact by conduction heat transfer with the TEGs. A steady-state quasi onedimensional heat conduction model with internal energy generation (in the TEG elements) is then solved to determine $\mathrm{T}_{\mathrm{c}}$. One boundary condition is the heat flux, $\mathrm{q}_{\mathrm{c}}$, at the spectral plate, and the other is a specified temperature, $T_{h}$, at the other junction of the TEGs. The equation includes the geometric and thermal characteristics of the TEG elements:

$$
\begin{aligned}
& \mathrm{q}_{\mathrm{c}} \eta \mathrm{A}_{\mathrm{r}}\left(\mathrm{A}_{\mathrm{p}}+\mathrm{A}_{\mathrm{n}}\right)=\kappa\left(\mathrm{T}_{\mathrm{h}}-\mathrm{T}_{\mathrm{c}}\right) \\
& \quad+\left(\left|\alpha_{\mathrm{n}}\right|+\left|\alpha_{\mathrm{p}}\right|\right) \mathrm{T}_{\mathrm{c}} \mathrm{I}_{\text {out }}+1 / 2 \mathrm{I}_{\text {out }} \mathrm{R},
\end{aligned}
$$

where $\eta$ is the efficiency of the CJP as the HTS, which overhangs the TEG module, $\kappa$ is the thermal conductance of a TEG junction pair,

$$
\kappa=\left(\lambda_{p} A_{p} / L_{p}\right)+\left(\lambda_{n} A_{n} / L_{n}\right)
$$

$\mathrm{R}$ is the TEG electrical resistance,

$$
R=\left(\rho_{n} L_{n} / A_{n}\right)+\left(\rho_{p} L_{p} / A_{p}\right)
$$

$A_{n}, A_{p}, L_{n}$, and $L_{p}$ are the respective cross-sectional areas and lengths of the n-type and p-type TEG materials, and $\alpha_{n}, \alpha_{p}, \rho_{n}, \rho_{p}, \gamma_{n}, \gamma_{p}$ are the respective Seebeck coefficients, electrical resistivities and thermal conductivities of the n-type and p-type TEG materials.
The area ratio $A_{r}=A_{S} / A_{e}$ is the area of the CJP (HTS), $A_{s}$, to the area of a TEG element, $A_{p}$ or $A_{n}$.

The theoretical power produced by the TEG module is determined from standard TEG equation analysis. 8,9 This is for an optimized figure of merit, Z, based on the TEG element's geometry and material properties.

Therefore the equation for the electrical current, $\mathrm{I}_{\text {out }}$, produced by the module is

$$
\mathrm{I}_{\text {out }}=\frac{\left(\left|\alpha_{\mathrm{p}}\right|+\left|\alpha_{\mathrm{n}}\right|\right)\left(\mathrm{T}_{\mathrm{h}}-\mathrm{T}_{\mathrm{c}}\right)}{\mathrm{R}[\mathrm{x}+1]},
$$

where $x=\left[1+\mathrm{Z}\left(\mathrm{T}_{\mathrm{h}}+\mathrm{T}_{\mathrm{c}}\right) / 2\right]^{1 / 2}$.

The open circuit voltage for the TEG module is

$$
\mathrm{V}_{\mathrm{oc}}=\left(\left|\alpha_{\mathrm{p}}\right|+\left(\alpha_{\mathrm{n}} \mid\right)\left[\mathrm{T}_{\mathrm{h}}-\mathrm{T}_{\mathrm{c}}\right]\right. \text {. }
$$

Hence the theoretical power from the TEG module can be determined.

\section{$\underline{\text { Heat Spreader }}$}

Investigation of the CJP as the HTS is modeled for three cases. (i) Shown in Figure 2(a) is a linear onedimensional approximation with radiation off one surface, providing a closed form solution which neglects corner effects. (ii) Figure 2(b) shows the radial approximation with a two-dimensional closed form solution for a square module with a round HTS. And (iii) Figure 2(c) shows the rectangular two-dimensional finite difference (FD) numerical model which includes the corner effects of the square HTS.

Shown in Figure 2(d) is the general coordinate system configuration used for the models. Heat input to the HTS occurs at the TEG module, on the opposite side from the radiation surface. Heat input takes place up to $\mathrm{L}_{\mathrm{m}}$. The HTS is then insulated to the end at $\mathrm{L}_{\mathrm{e}}$, with radiation along the full top surface as shown. The HTS analysis is then used with the Nighttime Solar Cell ${ }^{\text {TM }}$ thermal model to determine the device's electrical energy output.

\section{$\underline{\text { One-Dimensional Heat Spreader }}$}

Referring to Figure 2(b), the base temperature at the edge of the TEG module is $\mathrm{T}_{\mathrm{m}}$, at $\mathrm{y}=\mathrm{L}_{\mathrm{m}}$, and the end 
temperature of the HTS is $\mathrm{T}_{\mathrm{e}}$, at $\mathrm{y}=\mathrm{L}_{\mathrm{e}}$. Compared to the temperature of the HTS, deep space is $\sim 0 \mathrm{~K}$. The cross-sectional area of the HTS is tW. Therefore, the heat conduction equation for the HTS is

$$
d^{2} T / d y^{2}-\varepsilon \sigma T^{4} /\left(k_{s} t\right)=0
$$

with BCs: $\mathrm{T}=\mathrm{T}_{\mathrm{m}} @ \mathrm{y}=\mathrm{L}_{\mathrm{m}}$

$$
\mathrm{dT} / \mathrm{dy}=0 @ \mathrm{y}=\mathrm{L}_{\mathrm{e}} \text {, }
$$

where $\mathrm{k}_{\mathrm{S}}$ is the thermal conductivity of the HTS.

Redefining the variables as $\theta=\mathrm{T} / \mathrm{T}_{\mathrm{m}}$ and $\xi=\mathrm{y} / \mathrm{L}$, where $\mathrm{L}=\mathrm{L}_{\mathrm{e}}-\mathrm{L}_{\mathrm{m}}, \xi=0$ at $\mathrm{y}=\mathrm{L}_{\mathrm{m}}$ and $\xi=\mathrm{L}$ at $\mathrm{y}=\mathrm{L}_{\mathrm{e}}$. The equation becomes

$$
\mathrm{d}^{2} \theta / \mathrm{d} \xi^{2}-\mathrm{N} \theta^{4}=0
$$

with BCs: $\theta=1 @ \xi=0$

$$
\mathrm{d} \theta / \mathrm{d} \xi=0 @ \xi=1 \text {, }
$$

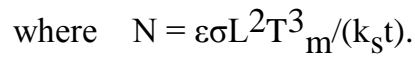

To solve, multiply by $\mathrm{d} \theta / \mathrm{d} \xi$, specify a first constant of integration based on an assumed tip temperature $T_{e}$, i.e., $\theta_{\mathrm{e}}=\mathrm{T}_{\mathrm{e}} / \mathrm{T}_{\mathrm{m}} @ \xi=1$. Define a new variable $\mathrm{Z}=\left(\theta_{\mathrm{e}} / \theta\right)^{5}$ to get $^{10}$

$$
\begin{aligned}
& {\left[(2 / 5) N \theta_{\mathrm{e}}\right]^{1 / 2} }= \\
& \mathrm{x}^{1} \\
&-\left(\theta_{\mathrm{e}} / 5\right) \bullet \mathrm{Z}^{\left.-7 / 10_{(1-Z}\right)^{-1 / 2} \mathrm{dZ}} \\
&\left(\theta_{\mathrm{e}}\right)^{5}
\end{aligned}
$$

This equation can be solved in terms of complete and incomplete Beta functions, solving for $\theta_{\mathrm{e}}$. The effectiveness of the heat spreader is defined as the ratio of the heat transferred by the actual CJP to the heat transferred if the entire CJP were at the temperature $\mathrm{T}_{\mathrm{m}}$.

\section{$\underline{\text { Two-Dimensional Heat Spreader }}$}

The radial model approximates the square module as circular with a round HTS, which provides a two- dimensional closed form solution. Steady state heat conduction is assumed in a cylindrical HTS of thickness $t_{d}$, and thermal conductivity $k_{d}$. The HTS of outside radius $\mathrm{L}_{\mathrm{e}}$ is heated by a circular heat source of strength $\mathrm{Q}$ centered at $\mathrm{r}=0$. The outside radius of the heat source is $\mathrm{L}_{\mathrm{m}}$. This is the heat conducted up through the TEG elements that produces the electric power in the TEG module.

The HTS is exposed to radiation cooling on the nonheated side to a sink temperature $T_{S}$ and is insulated on the opposite side. The view factor is assumed to be unity.

The heat conduction equation for the HTS temperature $\mathrm{T}$ is

$$
\begin{gathered}
\mathrm{k}_{\mathrm{d}} \mathrm{t}_{\mathrm{d}} \mathrm{d} / \mathrm{dr}[(1 / \mathrm{r}) \mathrm{dT} / \mathrm{dr}]+\mathrm{Srq}^{\prime \prime} \mathrm{o} \\
-\varepsilon \sigma r\left(\mathrm{~T}^{4}-\mathrm{T}_{\mathrm{s}}^{4}\right)=0
\end{gathered}
$$

where $\mathrm{q}^{\mathrm{g}} \mathrm{o}$ is the heat flux from the TEG module and S is 1 for $0 \leq \mathrm{r}<\mathrm{L}_{\mathrm{m}}$ and 0 for all other $\mathrm{r}$. The terms $\varepsilon$ and $\sigma$ are the emissivity of the HTS and the Stephan-Boltzmann constant respectively.

The temperature in Equation (7) is first scaled by the mean temperature of the HTS $\mathrm{T}_{\mathrm{m}}$, where a lumped energy balance on the spreader gives

$$
\mathrm{T}=\mathrm{T}_{\mathrm{S}}\left(1+\beta_{\mathrm{o}} \gamma_{\mathrm{o}}^{2}\right)^{1 / 4}
$$

where $\gamma$ is the aspect ratio $\mathrm{L}_{\mathrm{m}} / \mathrm{L}_{\mathrm{e}}$ and

$$
\beta_{\mathrm{o}}=\mathrm{q}_{\mathrm{o}} /\left(\varepsilon \sigma \mathrm{T}_{\mathrm{S}}^{4}\right)
$$

For the Nighttime Solar Cell ${ }^{\mathrm{TM}}$, the temperature variation over the radius of the HTS is not very large. Thus, the excursion of the dimensionless temperature, $\mathrm{T}(\mathrm{r}) / \mathrm{T}_{\mathrm{m}}$ is expected to be not too far from unity. Therefore let

$$
\mathrm{T}(\mathrm{r}) / \mathrm{T}_{\mathrm{m}}=1+\phi(\mathrm{r})
$$

where $|\phi(r)|<<1$, the radiation term in Equation (7) may be written as

$$
\left(\mathrm{T}(\mathrm{r}) / \mathrm{T}_{\mathrm{m}}\right)^{4}=(1+\phi(\mathrm{r}))^{4}=1+4 \phi(\mathrm{r})+\mathrm{O}(\phi(\mathrm{r}))^{2} .
$$


This linearization method is often used in radiation problems where the temperature variation is small.

Equation (7) is solved to obtain the solution for the temperature distribution in the HTS. ${ }^{11}$ The boundary conditions are adiabatic at $r=0$ and $r=L_{e}$. At the boundary $\mathrm{r}=\mathrm{L}_{\mathrm{m}}$, a match of the temperature and heat flux between the heated and unheated parts of the HTS is used.

In the solution, the typical $\mathrm{m}_{\mathrm{O}}$ parameter for a fin is used for the HTS where the heat transfer coefficient arises from radiation and not convection. The reference temperature in the radiative heat transfer coefficient is $T_{S}$, the temperature of deep space in the Nighttime Solar Cell ${ }^{\mathrm{TM}}$ application of the model.

The term is

$$
\mathrm{m}_{\mathrm{O}}=\left[4 \varepsilon \sigma \mathrm{T}_{\mathrm{s}}^{3} \mathrm{~L}_{\mathrm{e}}{ }^{\left.2 /\left(\mathrm{k}_{\mathrm{d}} \mathrm{t} \mathrm{d}\right)\right]^{1 / 2}}\right.
$$

The solutions of Equation (7) provide the temperature field in the HTS with radiation off the top surface for both the region with a heat source from the center at $\mathrm{r}=0$ to $\mathrm{r}=\mathrm{L}_{\mathrm{m}}$, and for the HTS with no heat source from $\mathrm{r}=\mathrm{L}_{\mathrm{m}}$ to $\mathrm{r}=\mathrm{L}_{\mathrm{e}}$. The solution of Equation (7) can provide the peak temperature of the HTS at $r=0$ shown in Equation (A-1) of Appendix $A$ as $T_{1}$,peak $/ T_{S}$. The average temperature of the HTS over the heated or TEG module portion of the HTS is shown in Equation (A-2) as $\mathrm{T}_{1 \text {, ave }} / \mathrm{T}_{\mathrm{S}}$. Hence $\mathrm{T}_{1 \text {, ave }}$ is the temperature of the cold junctions of the TEG module, that is, $T_{c}$, thus

$$
\mathrm{T}_{1, \mathrm{ave}}=\mathrm{T}_{\mathrm{c}}
$$

Therefore Equations (A-1) and (A-2) are used to present the temperature field for the case of the radial HTS with the approximated round module.

Now consider the two-dimensional FD case of Figure 2(c) where both the TEG module and the HTS are square. To distinguish the FD case, the square HTS has a dimension of $2 \mathrm{~L}_{2}$ having a centered square TEG module as a heat source of dimension $2 \mathrm{~L}_{1}$. For the analysis, we require that the areas for the HTS and the heater or TEG module be the same as for the cylindrical model from above, therefore

$$
\mathrm{L}_{\mathrm{e}}=\left(2 / \pi^{1 / 2}\right) \mathrm{L}_{2}
$$

and

$$
\gamma=\mathrm{L}_{1} / \mathrm{L}_{2}
$$

The parameter $\beta_{\mathrm{o}}$ remains as defined previously.

For this case, Equation (8) becomes with Equation (9)

$$
\mathrm{m}_{\mathrm{o}}=4\left[\varepsilon \sigma \mathrm{T}_{\mathrm{s}}^{3} \mathrm{~L}_{2}^{2} /\left(\pi \mathrm{k}_{\mathrm{d}} \mathrm{t}_{\mathrm{d}}\right)\right]^{1 / 2}
$$

With this information, the formulation of the FD solution for the rectangular HTS can be compared with the closed-form radial HTS solution.

\section{METHOD OF SOLUTION AND PARAMETERS}

Two sets of data are presented: (1) from the prototype Nighttime Solar Cell ${ }^{\mathrm{TM}}$ being built, predicted performance from the thermal model based on the geometries of the TEG module being used; and (2) HTS data from the one- and two-dimensional models, demonstrating the effect on cell performance based on HTS geometry, with a comparison of the underlying HTS model assumptions.

The performance of the model is presented using the TEG geometry of the prototype module being built, using Equations (1) through (5) from the previous research for the analysis. TEG cross-sectional area is confirmed, but element count and length are still to be determined for manufacturing capabilities. The module will be using $0.635 \mathrm{~mm} \times 0.635 \mathrm{~mm}$ TEG elements in the $1.5 \mathrm{~cm}$ to $2.5 \mathrm{~cm}$ length range, with 36 to 100 elements.

For the prototype, the CJP is $19.95 \mathrm{~cm}^{2}$ and the aperture opening is covered with a $\mathrm{ZnSe}$ window. The surface facing the nighttime sky is considered to have an emissivity of 0.94 . The model utilizes 12 transmission bands for radiative transfer through the atmosphere. ${ }^{5}$

The one-dimensional HTS geometry is varied for thickness $t_{d}$ from $1 \mathrm{~mm}$ to $6 \mathrm{~mm}$, with an extension beyond the TEG module of $1 \mathrm{~cm}$ to $6 \mathrm{~cm}$. Curve fits are used from Equation (6) for the relationship between $\mathrm{N}$ and the $\theta_{\mathrm{e}}{ }^{\prime} \mathrm{s}$ and the $\eta$ 's. Then for a selected HTS length $\mathrm{L}_{\mathrm{e}}$ and temperature at the module edge, $\mathrm{T}_{\mathrm{m}}, \theta_{\mathrm{e}}$ and $\eta$ are calculated for various fin thicknesses, $t_{d}$. 
The selected values of $\theta_{\mathrm{e}}$ are well within those calculated previously. These are then shown on the respective $\mathrm{t}$ vs $\theta_{\mathrm{e}}$ and $\mathrm{t}$ vs $\eta$ graphs.

For the two dimensional HTS model comparison, note that the temperature depends on the three dimensionless groups $m_{\mathrm{O}}, \beta_{\mathrm{O}}$ and $\gamma$. Plots of the peak temperature and average temperature of the HTS over the heated cylindrical part as a function of $\mathrm{m}_{\mathrm{O}}$ for two different values of $\gamma$ and $\beta_{\mathrm{O}}$ are presented. The radial HTS solution approximates the square TEG module or heater as cylindrical.

For the 2-D FD model, second-order finite difference approximations are used for derivatives. Radiation, based on local temperature at each node, is modeled exactly. The solution is carried out using matrix methods and iteration with under-relaxation, where the relaxation factor is 0.95 . A grid of 41 by 41 nodes is sufficient to ensure a virtually unchanging solution with further grid refinement.

\section{$\underline{\text { RESULTS }}$}

For the 1-D heat spreader analysis, the solution of Equation (6) is shown in Figure 3(a) for $\mathrm{N}$ vs $\theta_{\mathrm{e}}$ and $\mathrm{N}$ vs $\eta$. Both the end temperature and the thermal effectiveness of the HTS drop off very quickly for $\mathrm{N}<0.3$. In the geometries considered for the $6 \mathrm{~cm} x$ $6 \mathrm{~cm}$ cell, the region where $\mathrm{N}<0.1$ will be most influential, hence where $\theta_{\mathrm{e}}$ and $\eta$ are changing the most.

Figures 3(b) and 3(c) show the results for an aluminum HTS with typical Nighttime Solar Cell ${ }^{\mathrm{TM}}$ geometries. Therefore even very thin ( $1 \mathrm{~mm}$ to $2 \mathrm{~mm}$ ) aluminum HTSs can be used with less than a $2 \%$ to $3 \%$ change in its effectiveness, as shown from the curves.

Figure 4 illustrates the performance characteristics of the prototype cell once element count and length have been determined. One interesting aspect of the cell performance not noted before is the power increase for reduced element length, for optimized junction count.

The 2-D HTS model shows in Figure (5) the module average temperature ratio and in Figure (6) the peak temperature ratio. As seen in the figures, both ratios increase for increasing $\mathrm{m}_{\mathrm{O}}, \gamma$ and $\beta_{\mathrm{O}}$. The 2-D rectangular FD HTS model is also shown on the figures for comparison with the cylindrical model. All model curve characteristics and trends are as expected.

\section{$\underline{\text { DISCUSSION }}$}

The analysis shows that the previous presumed design of an HTS in the $6 \mathrm{~mm}$ to $8 \mathrm{~mm}$ thickness range is not necessary. In fact cell performance will be affected only slightly by making the HTS thin ( $1 \mathrm{~mm}$ to $2 \mathrm{~mm}$ ). This also leaves the door open for a copper HTS with a higher thermal conductivity, although a heavier material. However, more research is needed to determine a spectral radiative coating for the HTS surface that will be facing deep space, and will function well in a vacuum.

The increased "overhang" and added surface area of the larger HTS will improve cell output considerably. The radiative link between the cell and the thermal sink has already been demonstrated to be a strong function of HTS (CJP) surface area. ${ }^{3}$ This analysis shows that the HTS "fin" effectiveness remains quite high (>96\%) for a $2 \mathrm{~mm}$ thick (thin) HTS with a $5 \mathrm{~cm}$ overhang (large surface area HTS). Therefore many small junctions with large HTSs will increase voltage output of the cell significantly. This puts nanotechnology at the forefront of making high-density modules, that is, many very small junctions in close proximity, extremely promising for future Nighttime Solar Cell ${ }^{\text {TM }}$ performance.

Although the 1-D HTS model neglects corner effects, thermal characteristics and geometric trends for the prototype were used as a first approximation, and verified by the 2-D model. As shown in Figure (6), the peak temperature increases with increasing $\mathrm{m}_{\mathrm{O}}$ (as the conductance of the HTS decreases or the sink temperature $\mathrm{T}_{\mathrm{S}}$ increases). The peak temperature also increases with increases in $\gamma$ and $\beta_{\mathrm{O}}$. In the latter case, an increase in $\beta_{\mathrm{o}}$ is associated with an increase in the heat flux from the model which, intuitively, will result in increased peak temperature. For the former, increasing $\gamma$ increases the area over which the heat flux is applied, hence less surface area to dissipate the energy.

Finally, in Figures (5) and (6), both the peak and average temperatures in the square geometry are nearly identical to those for the cylindrical case. Clearly, T(r) $=\mathrm{T}(\mathrm{y})=\mathrm{T}(\mathrm{z})$ to a good degree of approximation for the range of parameters appearing in the figures. Thus we can conclude that the closed-form results provided by the cylindrical HTS solution (with the associated 
Bessel functions) presented above are valid for a square HTS and TEG module (or thermal source) for at least the following ranges: $\mathrm{m}_{\mathrm{O}} \leq 2, \gamma \leq 0.5$, and $\beta_{\mathrm{o}} \leq 10$, which are well within the parameters for the design characteristics for the Nighttime Solar Cell ${ }^{\mathrm{TM}}$.

The HTS curves reveal that because the heat flux $\mathrm{q}{ }_{\mathrm{o}}$ is so small from the TEG module, typically on the order of $10 \mathrm{~mW}$, the HTS can be very thin with little loss in effectiveness. Also, the HTS surface area can almost always be maximized for any given surface area constraint other than thermal considerations. This bodes well for future cell design.

\section{CONCLUSIONS}

Although HTSs have been used primarily for conduction and/or convection heat transfer in dissipating waste heat from high power electrical equipment, the Nighttime Solar Cell ${ }^{\mathrm{TM}}$ allows for the use of a radiative HTS in this low wattage application.

For TEG elements with high slenderness ratios where weight is of prime concern, the analysis shows that very thin (hence light) HTSs can be used with little loss in performance.

In applications where many very small TEG junctions can be used, the surface area of the HTS (size increase) will improve considerably the voltage output of the cell with little degradation to overall cell performance.

Originally, aluminum HTSs (or CJPs) on the order of $6 \mathrm{~mm}$ to $7 \mathrm{~mm}$ thick were contemplated and used on some simple bench models. But now higher conducting, but much heavier copper can be used with less concern for weight. Also, less expensive carbon steel can be used with slight degradation of thermal performance. Thus, optimizing HTS thickness (or surface area) is almost inconsequential.

Nighttime Solar Cell ${ }^{\mathrm{TM}}$ power requirements can be optimized at higher power densities using shorter TEG elements. With added TEG junction densities utilizing nanotechnology, cell performance and output can be increased significantly.

\section{DEDICATION}

The authors dedicate their research to Eric Jones and Joey Parise, two very talented young teens. Although barely acquainted in this lifetime, they can now play baseball forever together in their "Field of Dreams". God rest their souls.

\section{REFERENCES}

1. Parise, R.J., 1998, Nighttime Solar Cell ${ }^{\text {TM }}$, IECEC98, Colorado Springs, CO, Paper No. IECEC98-133.

2. Parise, R.J., 1999, "Nighttime Solar Cell", United States Patent No. 5,936,193.

3. Parise, R.J., Jones, G.F., Strayer, B., 1999, Prototype Nighttime Solar Cell ${ }^{\mathrm{TM}}$, Electrical Energy Production from the Night Sky, IECEC99, Vancouver, British Columbia, Canada, Paper No. 1999-01-2566.

4. Parise, R.J. and Jones, G.F., 2000, Energy from Deep Space - The Nighttime Solar Cell ${ }^{\mathrm{TM}}$ - Electrical Energy Production, IECEC00, Las Vegas, Nevada, Paper No. AIAA-2000-2822.

5. Parise, R.J. and Jones, G.F., 2001, "Nighttime and Daytime Electrical Energy Production from the Nighttime Solar Cell ${ }^{\mathrm{TM}}$, Proc. IECEC01, Savannah, GA, July 24-27, 2001.

6. Avenas, Y., Ivanova, M., Popova, N., Schaeffer, C., Schanen, J-.L, and Bricard, A., 2002, "Thermal Analysis of Thermal Spreaders Used in Power Electronics Cooling", Conference Record, IAS Annual Meeting (IEEE Industry Applications Society) V.1, pp.216-221.

7. Jagannadham, K., Watkins, T.R. and Dinwiddie, R.B., 2002, "Novel Heat Spreader Coatings for High Power Electronic Devices", Jour. of Materials Science, V.37, n.7, 4/1/02, pp. 1363-1376.

8. Culp, A.W., Jr., 1979, Principles of Energy Conversion, McGraw-Hill Book Company, New York, NY.

9. Angrist, S.W., 1982, Direct Energy Conversion, Fourth Edition, Allyn and Bacon, Inc., Boston, Massachusetts.

10. Love, T.J., 1968, Radiative Heat Transfer, Charles E. Merrill Publishing Co., Columbus, Ohio.

11. Arpaci, V. S., 1966, Conduction Heat Transfer, Addison-Wesley, Reading, MA. 


\section{Appendix A}

Solution to Equation (7):

$$
\begin{aligned}
& \frac{\mathrm{T}_{1, \text { peak }}}{\mathrm{T}_{\mathrm{S}}}=\left[1+\frac{\beta_{\mathrm{o}}\left(1-\gamma^{2}\right)}{4\left(1+\beta_{\mathrm{o}} \gamma^{2}\right)}+\mathrm{C}_{1}\right]\left(1+\beta_{\mathrm{o}} \gamma^{2}\right)^{1 / 4} \\
& \frac{\mathrm{T}_{1, \text { avg }}}{\mathrm{T}_{\mathrm{S}}}=\left[1+\frac{\beta_{\mathrm{o}}\left(1-\gamma^{2}\right)}{4\left(1+\beta_{\mathrm{o}} \gamma^{2}\right)}+\frac{2 \mathrm{C}_{1} \mathrm{I}_{\mathrm{o}}\left(\mathrm{m}_{\mathrm{o}} f \gamma\right)}{\mathrm{m}_{\mathrm{o}} f \gamma}\right]\left(1+\beta_{\mathrm{o}} \gamma^{2}\right)^{1 / 4}
\end{aligned}
$$

where

$$
\begin{aligned}
& \mathrm{C}_{1}=\frac{\beta_{\mathrm{o}}}{4\left(1+\beta_{\mathrm{o}} \gamma^{2}\right)}\left\{\mathrm { I } _ { \mathrm { o } } ( \mathrm { m } _ { \mathrm { o } } f \gamma ) \left[\frac{\mathrm{K}_{1}\left(\mathrm{~m}_{\mathrm{o}} f\right)}{\mathrm{I}_{1}\left(\mathrm{~m}_{\mathrm{o}} f\right)}\right.\right. \\
& \left.\left.\left.\quad+\frac{\mathrm{K}_{\mathrm{o}}\left(\mathrm{m}_{\mathrm{o}} f \gamma\right)}{\mathrm{I}_{\mathrm{o}}\left(\mathrm{m}_{\mathrm{o}} f \gamma\right)}\right]\left[\frac{\mathrm{K}_{1}\left(\mathrm{~m}_{\mathrm{o}} f\right)}{\mathrm{I}_{1}\left(\mathrm{~m}_{\mathrm{o}} f\right)}-\frac{\mathrm{K}_{1}\left(\mathrm{~m}_{\mathrm{o}} f \gamma\right)}{\mathrm{I}_{1}\left(\mathrm{~m}_{\mathrm{o}} f \gamma\right)}\right]^{-1}-1\right]\right\}^{-1} \\
& f=\left(\frac{\mathrm{T}_{\mathrm{m}}}{\mathrm{T}_{\mathrm{s}}}\right)^{3 / 2}=\left(1+\beta_{\mathrm{o}} \gamma^{2}\right)^{3 / 8}
\end{aligned}
$$

and $\mathrm{I}, \mathrm{K}$ are Bessel functions, and all other variables as defined in text.

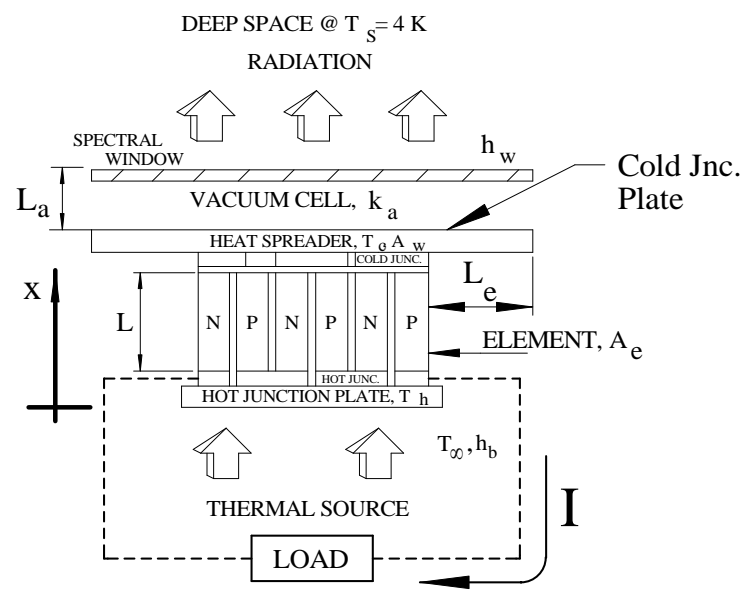

Figure 1: Schematic of Cell Configuration and Operation. 


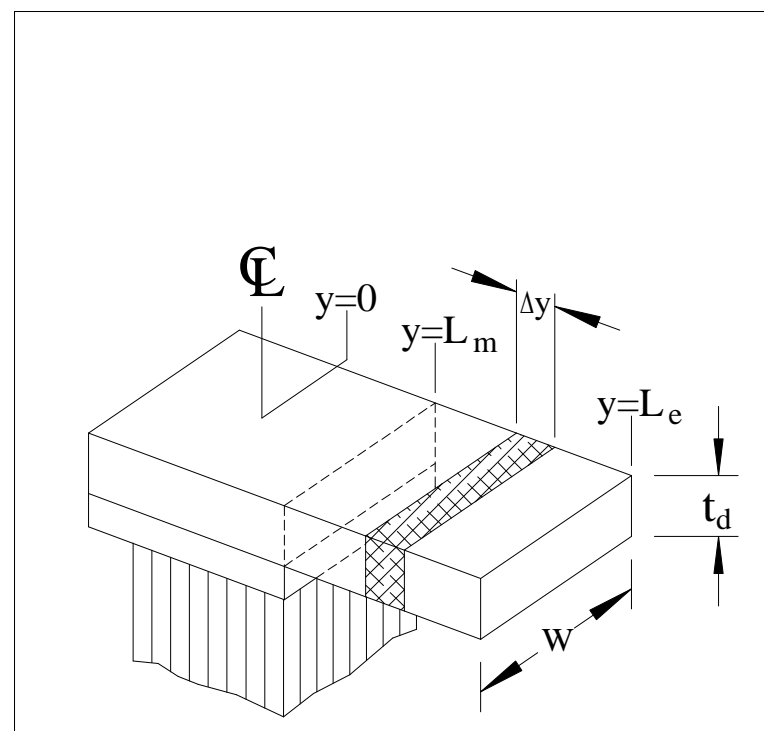

TEG Module

Figure 2(a):

One-Dimensional Model

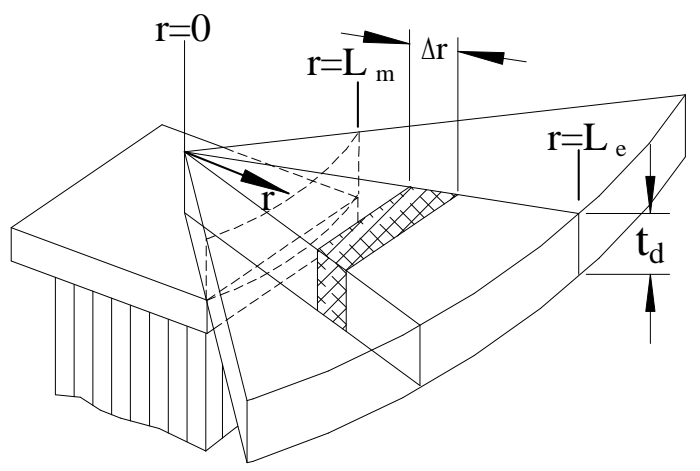

TEG Module
Figure 2(b) Radial Model

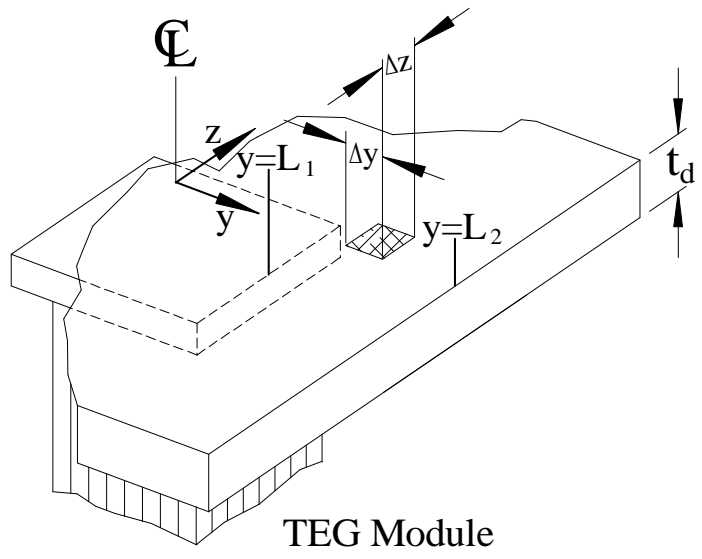

Figure 2(c) Two-Dimensioanl Model
Figure 2(d): General Coordinate System 


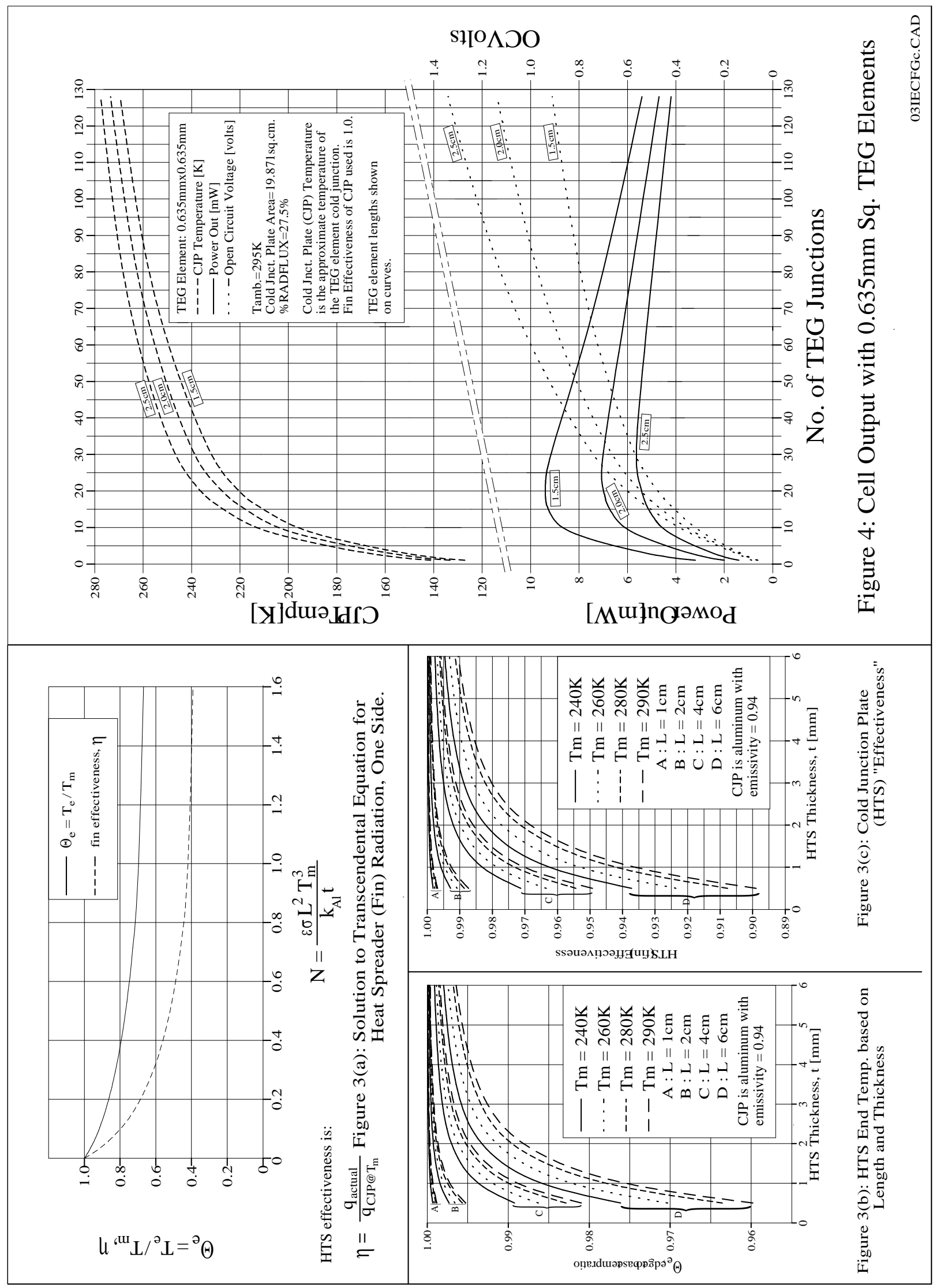




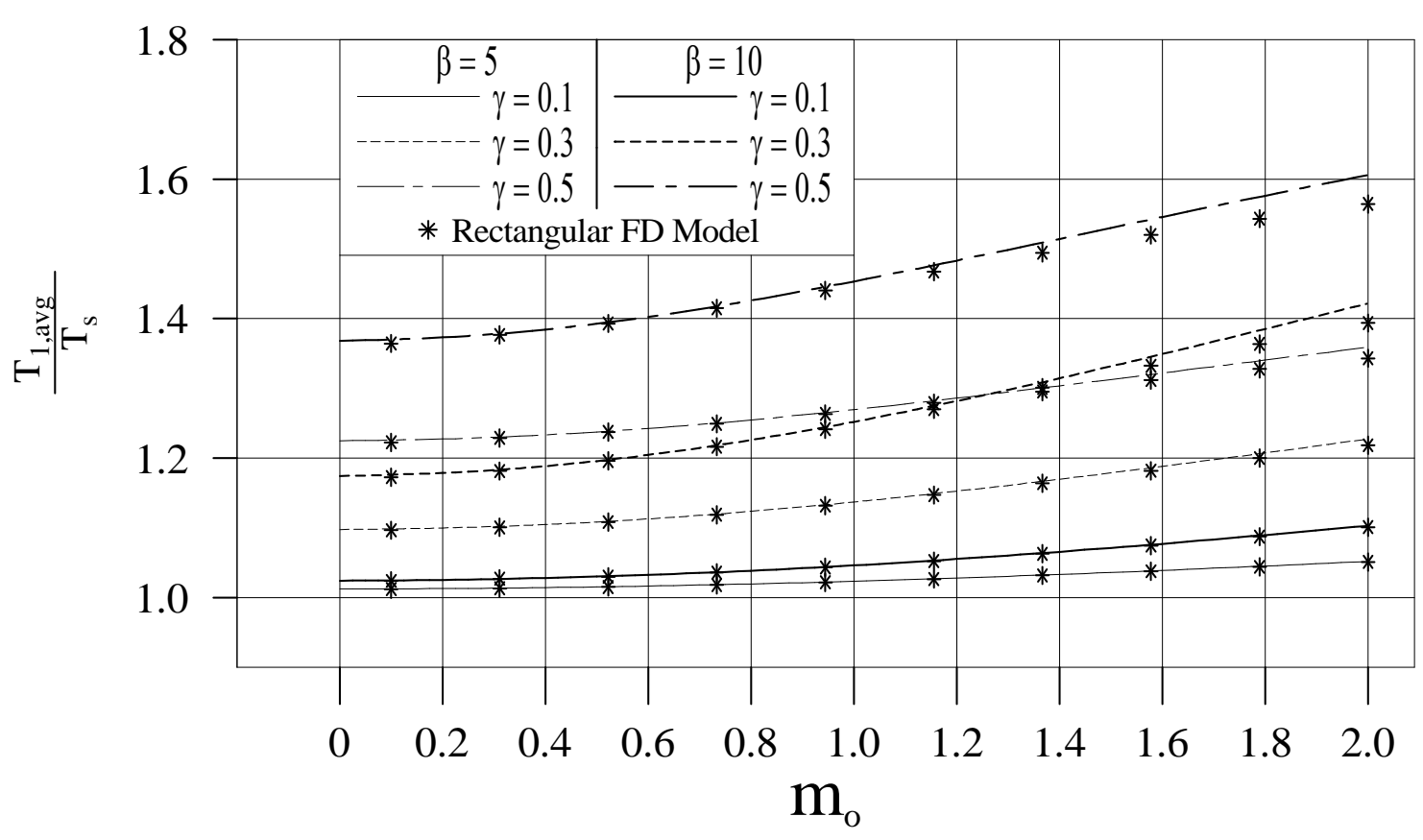

Figure 5: Ratio of heat source average temp (TEG cold junctions) to thermal sink temp (deep space).

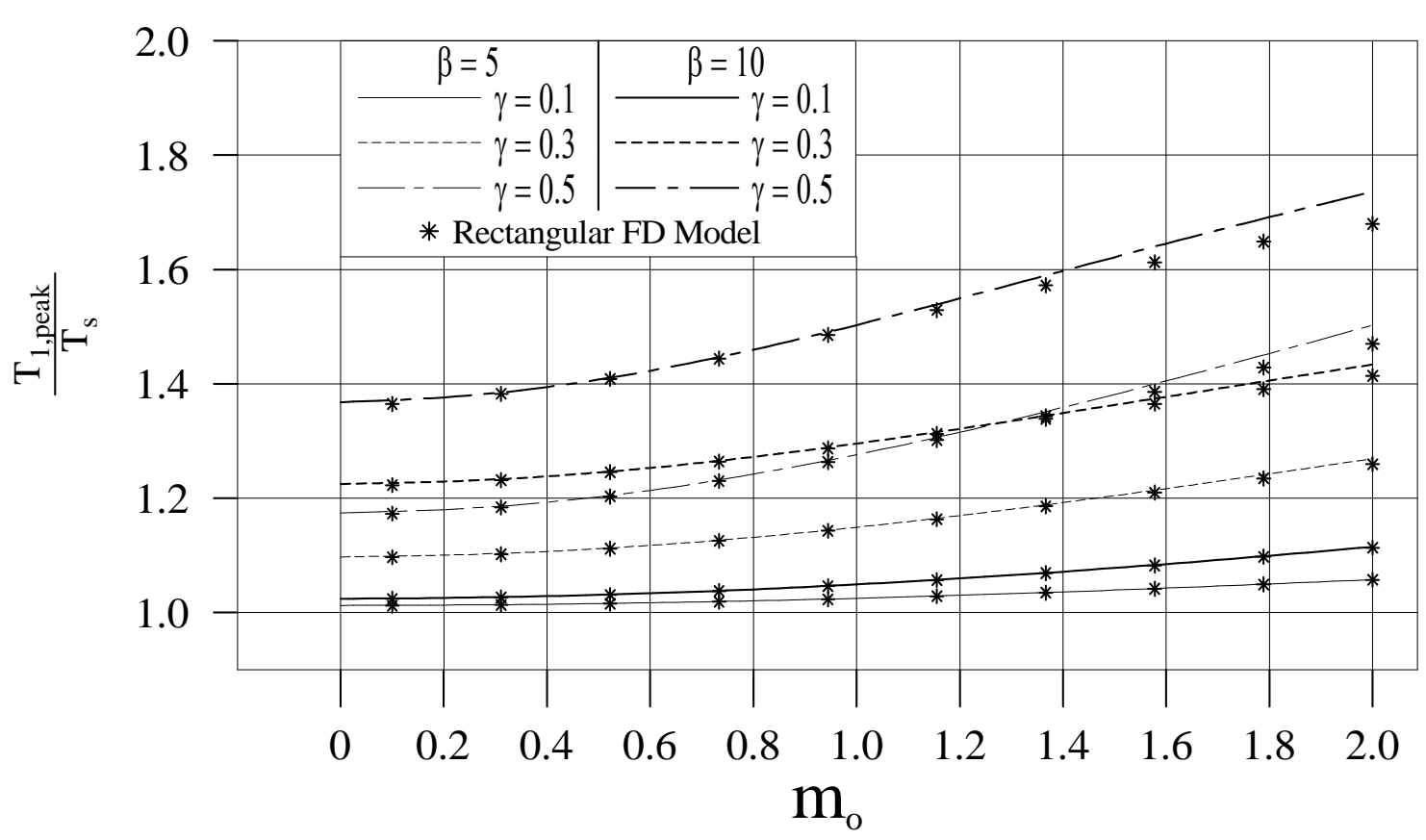

Figure 6: Ratio of heat source peak temp (Max TEG cold jcn. temps) to thermal sink temp (deep space). 